Adv. Geosci., 9, 85-91, 2006

www.adv-geosci.net/9/85/2006/

(C) Author(s) 2006. This work is licensed

under a Creative Commons License.

\title{
Integration of water balance models in RIVERTWIN
}

\author{
J. Götzinger, J. Jagelke, R. Barthel, and A. Bárdossy \\ Institute for Hydraulic Engineering, Universitaet Stuttgart, Germany \\ Received: 23 January 2006 - Revised: 22 May 2006 - Accepted: 3 July 2006 - Published: 26 September 2006
}

\begin{abstract}
In the project RIVERTWIN climate, hydrologic, groundwater and water quality models are integrated in order to evaluate river basin management plans established for the implementation of the EU Water Framework Directive. In such integrated models, which try to simulate all relevant processes in a river basin realistically, modelling of the water balance plays a key role. Therefore the integration of hydrological and groundwater models requires special attention. In this case study, the hydrological model simulates discharge and daily groundwater recharge in a high spatial resolution. Using the latter as input, the groundwater model calculates groundwater levels and groundwater runoff, which is then returned to the hydrological model. Such integration on the meso-scale brings up new problems such as commensurability, verification and compatibility of internal state variables and fluxes, but also provides the possibility to analyse the underlying assumptions and simplifications. As an example of this modelling approach the simulation of groundwater recharge, groundwater levels and groundwater runoff in the Neckar catchment are discussed and the problems of the current integration concept are described.
\end{abstract}

\section{Introduction}

The EU Water Framework Directive and the EU Water Initiative for the Millennium Development Goals have posed new questions for hydrological research in the past few years. Besides the many European projects supporting the implementation of this directive (Kämäri, 2006; Refsgaard, 2002; http://www.harmoni-ca.info/), the challenges mentioned above have lead to considerable effort in predicting the impact of global change on river basins and their management (Zehe and Bárdossy, 2002; Gaiser et al., 2003;

Correspondence to: J. Götzinger

(jens.goetzinger@iws.uni-stuttgart.de) http://www.glowa.org/; http://www.kliwa.de/; Stock, 2005). Most of these projects face similar problems when models from different disciplines are integrated. The interfaces have to be clearly defined and often compromises have to be made between the demands of the models, the data availability and the objectives of the study. A common problem is also that input and state variables are sparse or missing in the desired resolution. If the fluxes between models cannot be measured at all, innovative solutions have to be found to represent the natural system in a realistic way. As an example, the integrated modelling of groundwater recharge and groundwater runoff in the meso-scale Neckar basin $\left(14000 \mathrm{~km}^{2}\right)$ is discussed in this paper. For smaller scales similar studies have shown that the integration of different models is possible (Bronstert et al., 2005). However on a larger scale, additional problems emerge some of which are discussed here (see also Barthel et al., 2005).

As a result of the equifinality discussion (Beven and Binley, 1992), it has been proposed to reduce parameter uncertainty by using multi-response data or multi-criteria calibration. Kuczera and Mroczkowski (1998) observed that augmenting stream flow data with groundwater level data did not improve the identifiability of a nine parameter conceptual model. On the other hand, the use of stream salinity data in addition to stream flow data in the calibration process substantially reduced the parameter uncertainty in their study. Seibert (2000) discovered that the parameters of "HBV light" were significantly constrained when calibrated against stream flow and groundwater level data. For one of the catchments considered in the study the multi-criteria calibration even led to an improvement of the model structure.

As many conceptual hydrological models simulate the groundwater contribution by a linear storage reservoir, the integration of a physically based groundwater model should improve the modelling results and lead to more realistic projections for the future. Earlier studies have also shown that uncertainty largely depends on input data, errors in the

Published by Copernicus GmbH on behalf of the European Geosciences Union. 
conceptual model (scale and abstraction) or commensurability issues (Beven and Binley, 1992). Integrating further models enables assumptions and simplifications of conceptual models to be analysed and a multi-response validation of the integrated model to be performed, which may provide more insight and trust in the results. Comparable to the mentioned studies, the integrated surface and groundwater models are calibrated against runoff and groundwater levels, respectively. But through the integration concept presented here they will also be conditioned to simulate the groundwater recharge and groundwater runoff in a model consistent way. By this indirect check on internal processes the uncertainty of the modelling complex can be reduced. Some of the problems encountered during the modelling process will be presented and discussed.

This study is part of the project "RIVERTWIN" which aims at adjusting, testing and implementing an integrated regional model for the strategic planning of water resources management in twinned river basins under contrasting ecological, social and economic conditions. The regional model takes into account the impacts of demographic trends, economic and technological development and the effects of global climate and land use changes on the availability and quality of water bodies in humid temperate, subhumid tropical as well as semiarid regions. The integration framework was tested in the European Neckar basin with high data availability and data density. The transferability of the model to other regions with different economic levels, ecological standards and with low data availability is currently being tested by the project team and river basin organisations in two river basins, in West Africa (Benin) and Central Asia (Uzbekistan). More detailed information can be found under http://www.rivertwin.de.

\section{The models HBV, LARSIM and MODFLOW}

A wide variety of hydrological models have been developed in the past century and are applied for water resources management (Singh, 1995). In order to quantify the effect of changing land use and climate with a high spatial and temporal resolution properly, the models have to fulfil certain criteria: They should be simple enough to work on large scales, with sparse data but also be able to simulate future climate scenarios. This is especially important for the model application in Benin and Uzbekistan in order to demonstrate the transferability of the concepts to other basins. At the same time, the model concept and parameterization should be based on a reasonable representation of the dominant catchment processes and should be able to reflect changes in catchment characteristics and forcing data. Therefore, a version of the semi-distributed conceptual HBV model (Bergström, 1995) was modified according to these requirements. The results are compared to the LARSIM model (Bremicker, 2000) which is operational at the State Institute for Environmental Protection Baden-Württemberg and was used in a regional climate change impact study focusing on floods (http://www.kliwa.de/).

The HBV model concept was developed by the Swedish Meteorological and Hydrological Institute (SMHI) in the early 1970's. It has conceptual routines for calculating snow accumulation and melt, soil moisture and runoff generation, runoff concentration within the subcatchment, and flood routing of the discharge in the river network. The snow routine uses the degree-day approach. Soil moisture is calculated by balancing precipitation and evapotranspiration using field capacity and permanent wilting point as parameters. Runoff generation is simulated by a nonlinear function of the actual soil moisture and precipitation. The runoff concentration is modelled by two parallel nonlinear reservoirs representing the direct discharge and the groundwater response. Flood routing between the river network nodes uses the Muskingum method. Additional information about the HBV model in general can be found in Uhlenbrook et al. (2004), Hundecha and Bárdossy (2004) and Hundecha (2005). The main modification of the version used in this study is that the runoff generation and concentration routines are fully distributed on a $1 \mathrm{~km}^{2}$ raster. Parameterization is achieved by regionalization using soil, topography and land use data. As the parameterization is not the main focus of this paper the reader is referred to Götzinger and Bárdossy (2005).

The water balance model LARSIM (Large Area Runoff Simulation Model) is a mesoscale model developed to simulate the water balance of large river basins continuously. It incorporates the processes of interception, evapotranspiration, water storage in soils and aquifers, runoff generation in the catchment and translation and retention in river channels. Snow accumulation and snowmelt are taken into account as well as artificial influences (e.g. storage basins, diversions or water transfer between different basins). LARSIM combines deterministic hydrological model components that are generally applicable and based on available geographic and meteorologic data, like the Xinanjiang model (Zhao, 1977) or parallel linear storages (Bremicker and Gerlinger, 2000).

For modelling the groundwater flow the physically based 3-D finite difference groundwater flow model MODFLOW (McDonald and Harbaugh, 1988) is used, which is a very well verified code for mathematical modelling of saturated groundwater flow. MODFLOW is based on the horizontal and vertical discretisation of the modelling domain and solves the groundwater flow equation - derived from the law of conservation of mass and Darcy's law - for each discrete point in space and time taking into consideration recharge, as well as pumping and drainage from the given groundwater system. It enables the simulation of leakage between adjacent aquifers and can reproduce flowpaths in all three spatial directions. 


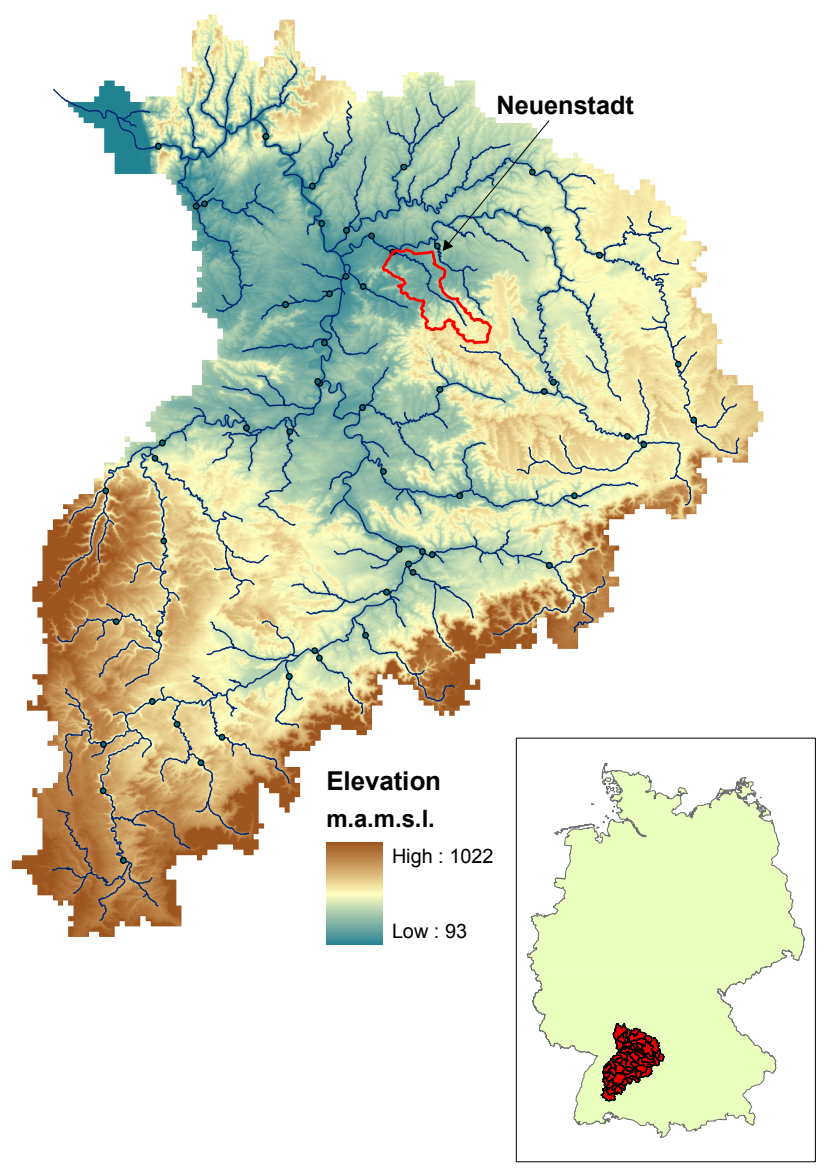

Fig. 1. Topography of the Neckar catchment and subcatchment Neuenstadt used in this study. Inset: Location of the Neckar catchment in Germany.

Soil, topography, land use and climate data

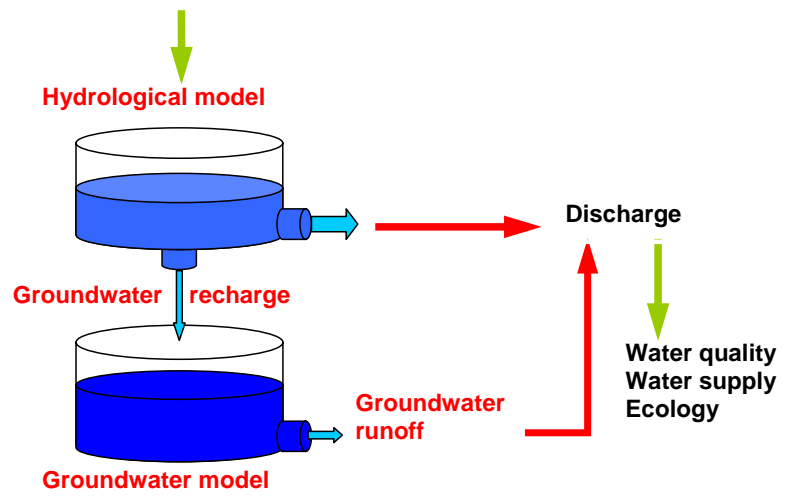

Fig. 2. The integration strategy of the surface and ground water models in RIVERTWIN.

\section{Data}

The Neckar basin, located in south-western Germany, covers an area of about $14000 \mathrm{~km}^{2}$. The elevation in the catch-

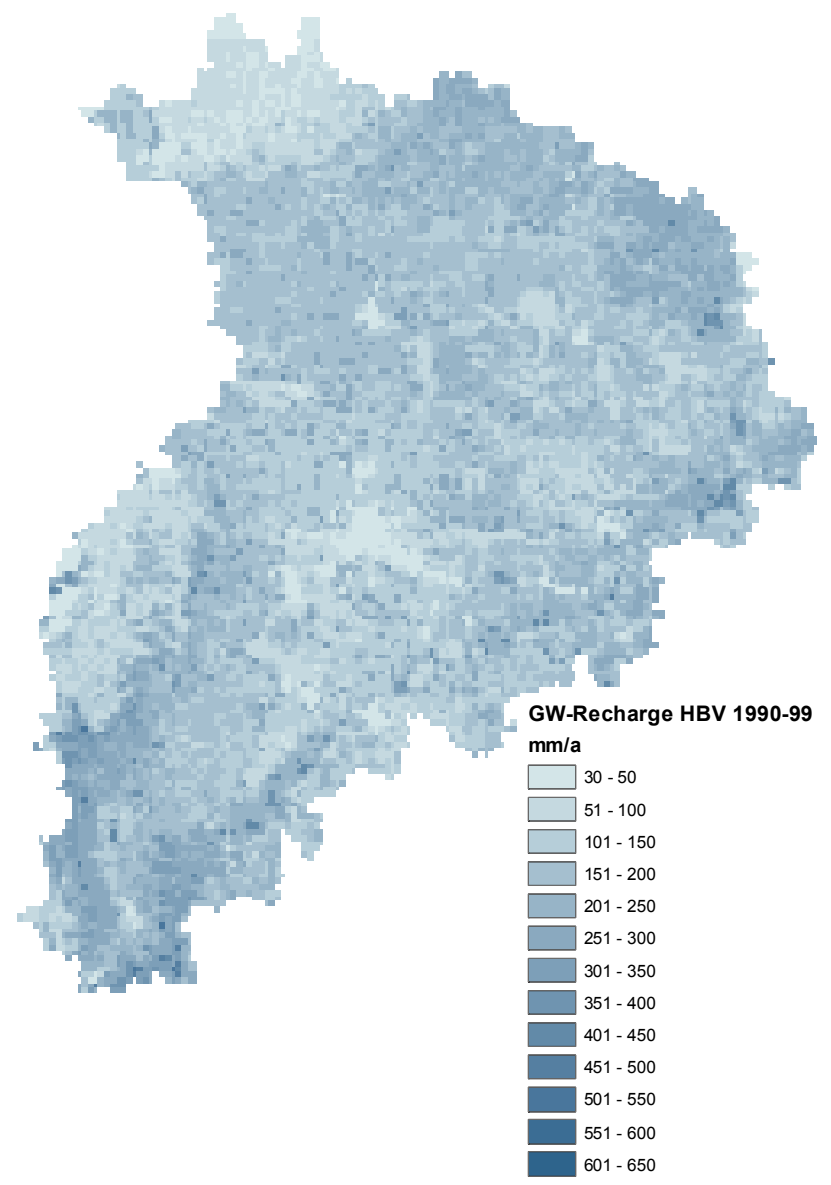

Fig. 3. Mean annual groundwater recharge in the Neckar basin simulated with $\mathrm{HBV}$.

ment varies from $93 \mathrm{~m}$ a.s.l at the catchment outlet to about $1022 \mathrm{~m}$ a.s.l in the Schwäbische Alb in the south of the catchment (Fig. 1). The climate can be characterized as humid with a long-term average annual precipitation of $950 \mathrm{~mm}$, ranging from $750 \mathrm{~mm}$ in the lower part to over $1200 \mathrm{~mm}$ in the Black Forest. Landuse (Landsat 1993, resolution $30 \mathrm{~m}$ ), soil (Bodenübersichtskarte 200, scale 1:200 000) and topographic data (resolution $50 \mathrm{~m}$ ) were aggregated to a uniform grid resolution $(1 \mathrm{~km})$. Precipitation and temperature data were interpolated by external drift kriging from observation station data. Discharge data from 58 gauging stations was used for model evaluation. All data was provided by the State Institute for Environmental Protection Baden-Württemberg.

\section{Integration methodology}

Figure 2 visualizes the selected integration strategy: Soil, topographic, land use and climatic data provide the parameters and driving forces of the hydrological model, which calculates discharge components and high resolution groundwater recharge rates. The latter serve as input for the groundwater 


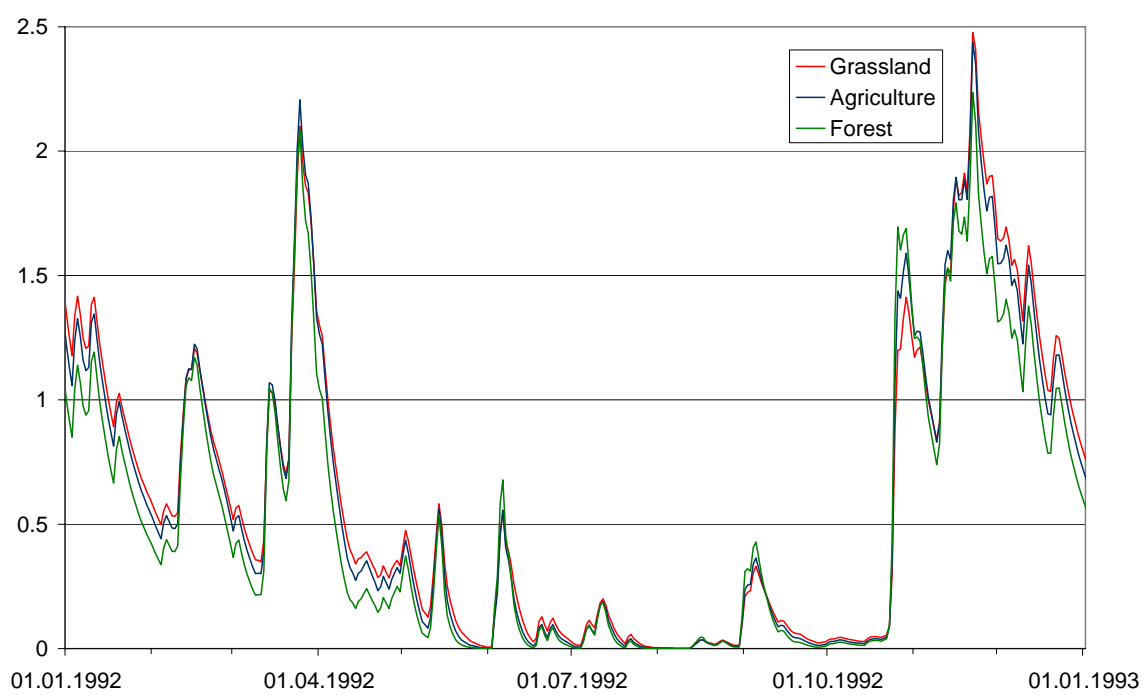

Fig. 4. Seasonal variation of groundwater recharge $(\mathrm{mm} / \mathrm{d})$ of three land use types simulated with HBV.

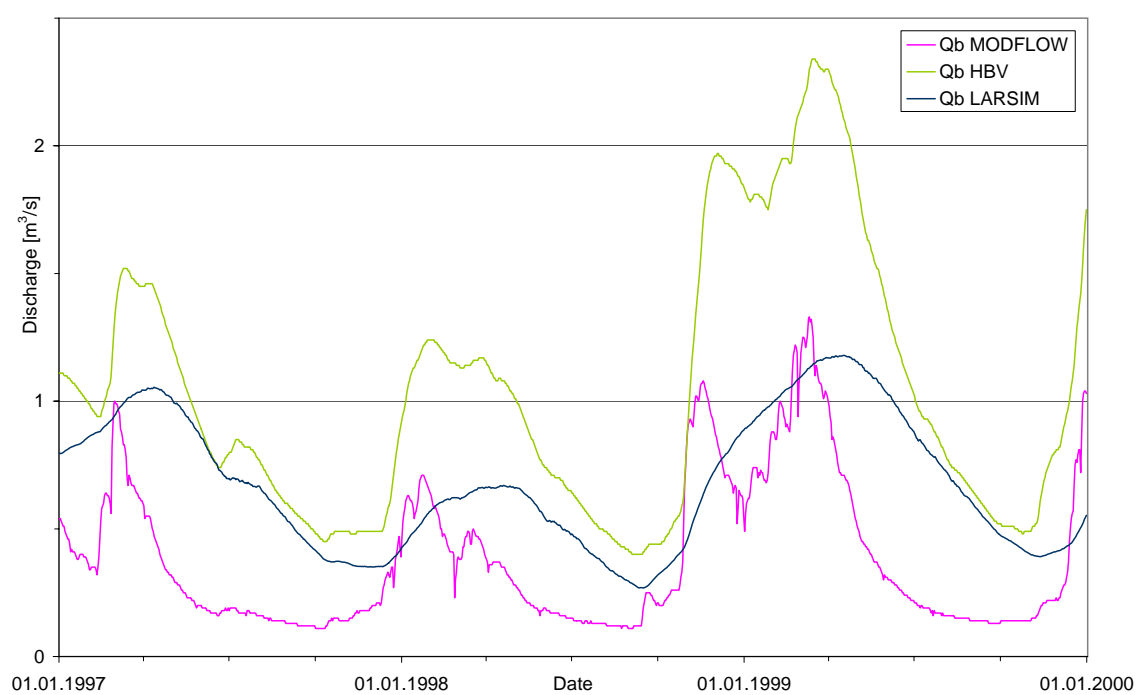

Fig. 5. Simulated groundwater runoff hydrographs of MODFLOW, HBV and LARSIM at Neuenstadt (1997-1999).

model which simulates, in addition to the groundwater levels, groundwater runoff in the stream network, which is used in the hydrological model as the groundwater component of the discharge. Capillary rise from the groundwater to the root zone is negligible on this scale in the Neckar basin and is therefore not included in the model integration. The simulated total discharge serves as input to water quality, ecological and water supply models. In contrast to the water balance models, no feedback is included between these models.

All models were calibrated individually. Both hydrological models were calibrated to fit the observed discharges and to provide a realistic estimate of groundwater recharge. The groundwater model was calibrated to fit the groundwater levels as well as to minimize the difference between the ground- water runoff simulated by the groundwater model and the hydrologic models. Including this groundwater runoff in the hydrologic model decreases the simulation efficiency of the total discharge. Nevertheless, the additional constraints on the individual models (groundwater recharge and groundwater runoff) reduce the degrees of freedom of the system which leads to lower model efficiency but increased confidence in the model structure and parameters.

\section{Results}

The simulation of groundwater recharge with HBV shows a high spatial variability, determined by climate, land use and soil type (Fig. 3). The seasonal variability, shown in 


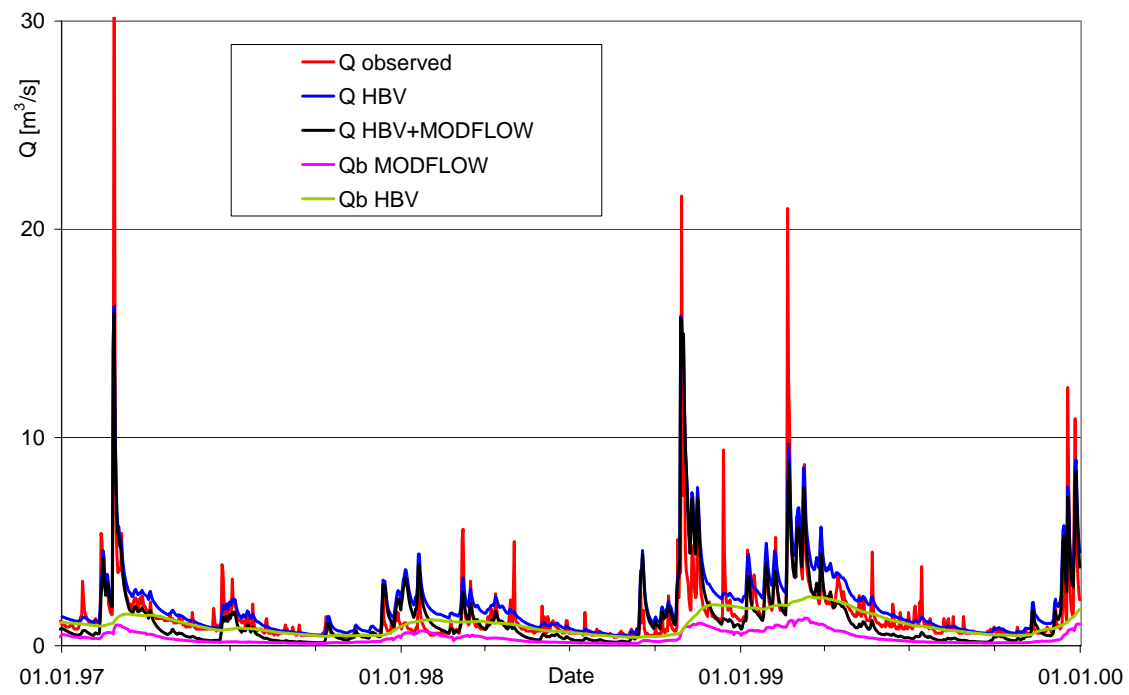

Fig. 6. Observed and simulated discharge at Neuenstadt (1997-1999), red: observation, blue: HBV, black: direct runoff from HBV plus groundwater runoff from MODFLOW, magenta: groundwater runoff simulated with MODFLOW, green: groundwater runoff simulated with HBV.

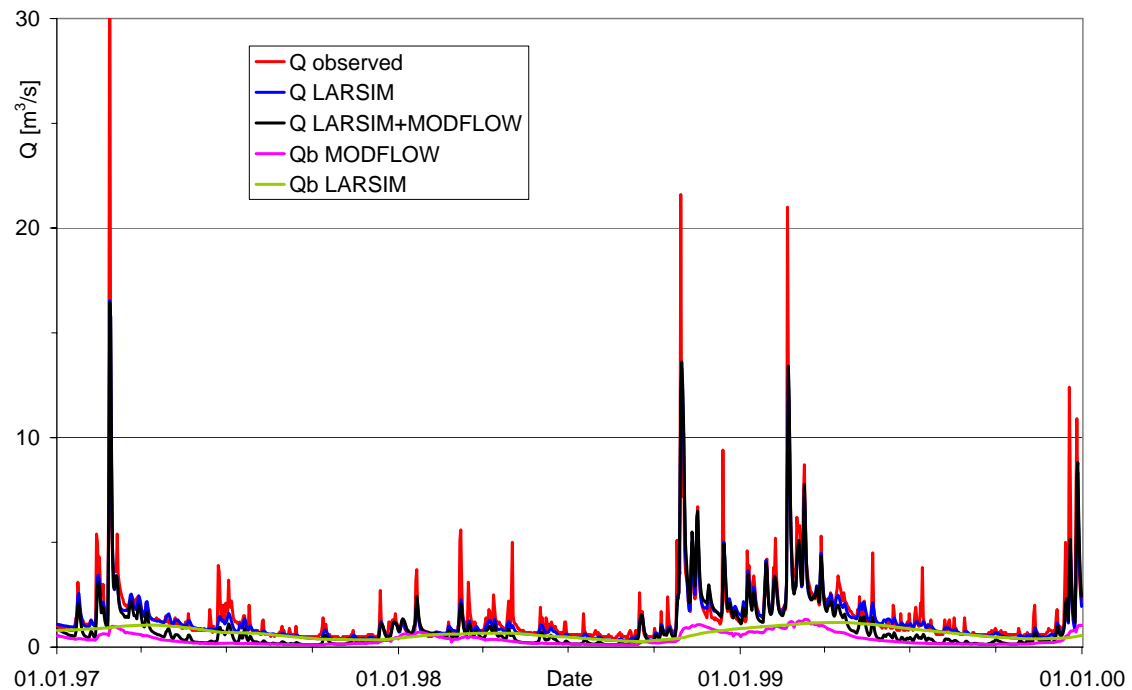

Fig. 7. Observed and simulated discharge at Neuenstadt (1997-1999), red: observation, blue: LARSIM, black: direct runoff from LARSIM plus groundwater runoff from MODFLOW, magenta: groundwater runoff simulated with MODFLOW, green: groundwater runoff simulated with LARSIM.

Fig. 4 for three distinct land use types with similar soil properties, is also quite high due to fluctuations in rainfall and evaporative demand. This groundwater recharge was used in MODFLOW to model the groundwater levels and runoff to the river system.

The groundwater runoff hydrographs simulated with MODFLOW, HBV and LARSIM display a similar magnitude and variability (Fig. 5). The simulated groundwater runoff hydrographs of LARSIM and particularly of HBV are systematically higher and more delayed than the MODFLOW hydrographs. As expected from a physically based model, MODFLOW shows a much more dynamic response than the linear reservoir models HBV and LARSIM. The differences between the two hydrological models stem from the varying separation into direct runoff and groundwater recharge. All three results are plausible compared to base flow separation methods, literature values and process understanding, and could be accepted since the true groundwater runoff cannot be measured directly on this scale. In fact, it is only a conceptual quantity that is always defined with respect to a certain context and scale. As the simulated discharge in this integrated model is used for river basin management, 
the groundwater runoff must primarily serve this purpose. This means that the groundwater runoff should fit well to the other simulated flow components. The hydrographs of the total discharge show that, especially in the low flow periods, the groundwater contribution influences the discharge significantly (Fig. 6 and Fig. 7). The Nash-Sutcliffe model efficiency of the HBV simulations is 0.55 compared to 0.73 for LARSIM. In some cases the integration of the groundwater model baseflow even increased the model efficiency (HBV: 0.58 in the integrated model compared to 0.55 in the original simulations). But in most cases it led to a reduced Nash Sutcliffe coefficient (LARSIM: 0.67 compared to 0.73). Nevertheless, the loss in accuracy is acceptable given the additional information that becomes available through the integration.

\section{Conclusions}

The integration of a hydrological and a groundwater model has shown that groundwater presents a significant contribution to the water balance of the Neckar catchment, especially in low flow periods. The use of simulated groundwater recharge as input to the groundwater model demonstrated that hydrological models can provide realistic estimations of this inflow to the groundwater system. The groundwater runoff simulated with a groundwater model reacted faster and was smaller than the one simulated with the two hydrological models. Theory and other studies indicate that, even on this scale, groundwater flow can be simulated with more reliance by a physical groundwater model than a conceptual linear storage reservoir (Rojanschi et al., 2006). Integrating these models, however, extends the demands on them but also the possibilities to verify the model concepts. Despite reduced simulation efficiency, this improved our trust in the models for the simulation of future climate or land use change impact scenarios. The presented examples have shown that model integration on the meso-scale is possible but brings up new problems which are currently being addressed in more detail. But it also opens up possibilities to improve models by multi-response validation and provides helpful insights into internal processes and model conceptualizations. The model integration is currently being improved and will then be used to simulate the impact of land use and climate change scenarios on the water balance of the Neckar catchment.

Acknowledgements. This research was funded by the European Union in the Sixth Framework Program through the project RIVERTWIN. Data and the model LARSIM were provided by the State Institute for Environmental Protection Baden-Württemberg. The valuable suggestions of two reviewers are greatly appreciated.

Edited by: R. Barthel, J. Götzinger, G. Hartmann, J. Jagelke, V. Rojanschi, and J. Wolf

Reviewed by: anonymous referees

\section{References}

Barthel, R., Rojanschi, V., Wolf, J., and Braun, J.: Large-scale water resources management within the framework of GLOWADanube, Part A: The groundwater model, Phys. Chem. Earth, 30, 6-7, 372-382, 2005.

Bergström, S.: The HBV model, in: Computer Models of Watershed Hydrology, edited by: Singh, V. P., Water Resources Pub., Littleton, CO, 443-476, 1995.

Beven, K. J. and Binley, A. M.: The future of distributed models: model calibration and uncertainty prediction, Hydrol. Processes, 6, 279-298, 1992.

Bronstert, A., Carrera, J., Kabat, P., and Lütkemeier, S.: Coupled models for the hydrological cycle, Springer, Heidelberg, Germany, 2005.

Bremicker, M.: Das Wasserhaushaltsmodell LARSIM - Modellgrundlagen und Anwendungsbeispiele, Institut für Hydrologie der Universität Freiburg, Freiburg, Germany, 2000.

Bremicker, M. and Gerlinger, K.: Operational application of the water balance model LARSIM in the Neckar basin, Institut für Hydrologie der Universität Freiburg, Freiburg, Germany, 2000.

Gaiser, T., Araújo, J. C., Frischkorn, H., and Krol, M. (Eds.): Global Change and Regional Impacts: Water Availability and Vulnerability of Ecosystems and Society in Semi-Arid Northeast of Brazil, Springer, Heidelberg, Germany, 2003.

Götzinger, J. and Bárdossy, A.: Integration and calibration of a conceptual rainfall-runoff model in the framework of a decision support system for river basin management, Adv. Geosci., 5, 1-5, 2005 , http://www.adv-geosci.net/5/1/2005/.

Hundecha, Y. and Bárdossy, A.: Modeling of the effect of land use changes on the runoff generation of a river basin through parameter regionalization of a watershed model, J. Hydrol., 292, 281-295, 2004.

Hundecha, Y.: Regionalization of Parameters of a Conceptual Rainfall-Runoff Model, Mitteilungsheft Nr. 142, Institut für Wasserbau der Universitaet Stuttgart, Stuttgart, Germany, 2005.

Kämäri, J.: BMW - Benchmark Models for the Water Framework Directive http://www.environment.fi/default.asp? contentid=116046 \\&lan=EN $\backslash \#$ a1, 09.01.2006.

Kuczera, G. and Mroczkowski, M.: Assessment of hydrologic parameter uncertainty and the worth of multiresponse data, Water Resour. Res., 34, 6, 1481-1489, 1998.

McDonald, M. G. and Harbaugh, A. W.: A modular threedimensional finite-difference ground-water flow model, Technical report, U.S. Geol. Survey, Reston, VA. USA, 1988.

Refsgaard, J. C. (Ed.): State-of-the-art report on quality assurance in modelling related to river basin management, HarmoniQuA Report, D-WP1-1, Copenhagen, Denmark, 2002.

Rojanschi, V., Wolf, J., and Barthel, R.: Calibration and Validation of an Integrated Hydrological Model Complex in the Ammer Catchment, Adv. Geosci., this volume, 2006.

Seibert, J.: Multi-criteria calibration of a conceptual runoff model using a genetic algorithm, Hydrol. Earth Syst. Sci., 4(2), 215224, 2000.

Singh, V. P. (Ed.): Computer Models of Watershed Hydrology, Water Resour. Publ., Littleton, Colorado, USA. 1995.

Stock, M. (Ed.): KLARA Klimawandel - Auswirkungen, Risiken, Anpassung, PIK Report No. 99, Potsdam, Germany, 2005. 
Uhlenbrook, S., Seibert, J., Leibundgut, C., and Rohde, A.: Prediction uncertainty of conceptual rainfall-runoff models caused by problems in identifying model parameters and structure, Hydrol. Sci. J., 44(5), 779-797, 2004.

Zhao, R. J.: Flood forecasting method for humid regions in China, East China Institute of Hydraulic Engineering, Nanjing, China, 1977.
Zehe, E. and Bárdossy, A.: Hydrological Impact of Climate Change on the River Rhine, Final report, in: IRMA-SPONGE "Development of flood management strategies for the Rhine and Meuse basins in the context of integrated river management" University of Stuttgart, Germany 2002. 